\title{
Should obstetricians working in non-endemic countries care about emerging tropical diseases? A review
}

\author{
Susanna Giachè ${ }^{1}$, Giulia Modi ${ }^{1}$, Beatrice Borchi ${ }^{1}$, Irene Campolmi ${ }^{1}$, Michele Trotta ${ }^{1}$, \\ Mariarosaria Di Tommaso ${ }^{2}$, Viola Seravalli ${ }^{3}$, Alessandro Bartoloni ${ }^{1}$, and Lorenzo \\ Zammarchi ${ }^{1}$
}

${ }^{1}$ Affiliation not available

${ }^{2}$ Careggi Hospital University of Florence

${ }^{3}$ University of Florence

October 9, 2020

\begin{abstract}
Due to migration and travels, obstetricians are increasingly faced with a globalized setting and should adapt their daily clinical approach to the modifications of tropical infections epidemiology. This paper is focused on five emerging infectious diseases, namely Chagas disease, HTLV-1 infection, malaria, schistosomiasis and Zika virus infection, having a high prevalence in migrant populations and which can affect international travelers. These diseases frequently pass unrecognized since they are characterized by few symptoms during pregnancy, however they may cause a relevant maternal, fetal and neonatal impact. Specific diagnostic and treatment options are available but are rarely used during routine obstetrical practice.
\end{abstract}

\section{Hosted file}

Main Document.pdf available at https://authorea.com/users/365764/articles/485739-shouldobstetricians-working-in-non-endemic-countries-care-about-emerging-tropical-diseases-areview 


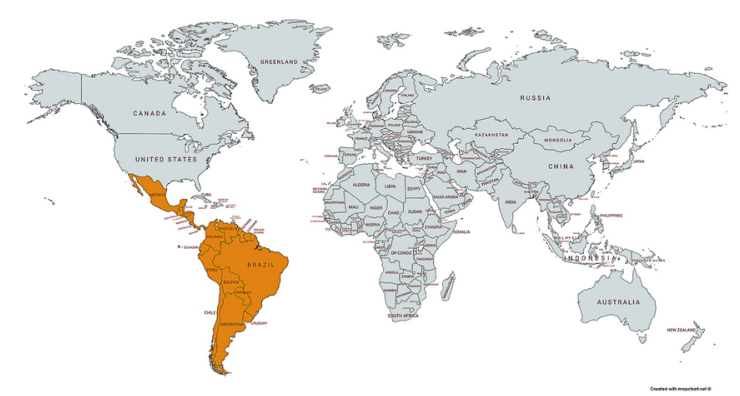

Panel A. Endemic countries for Chagas disease [0]

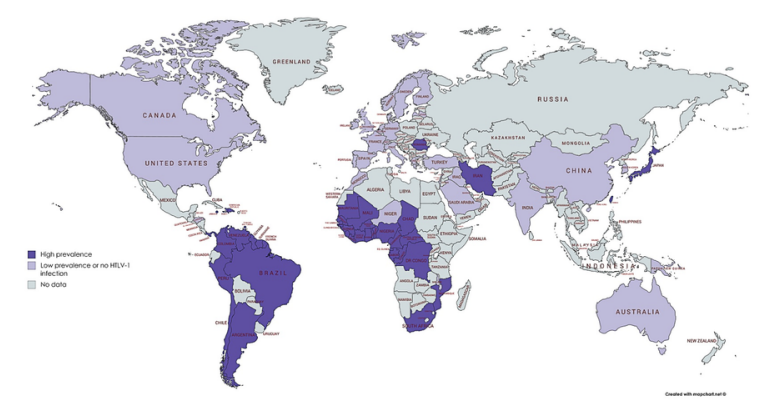

Panel B. Global distribution of HTLV-1 infection [31]

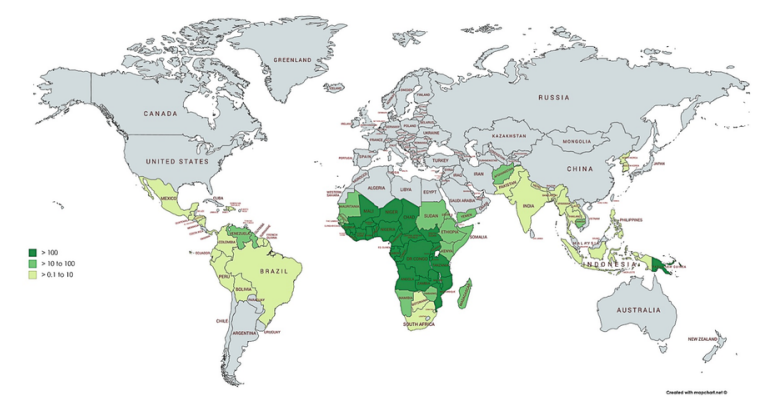

Panel C. Global distribution of malaria [38] 


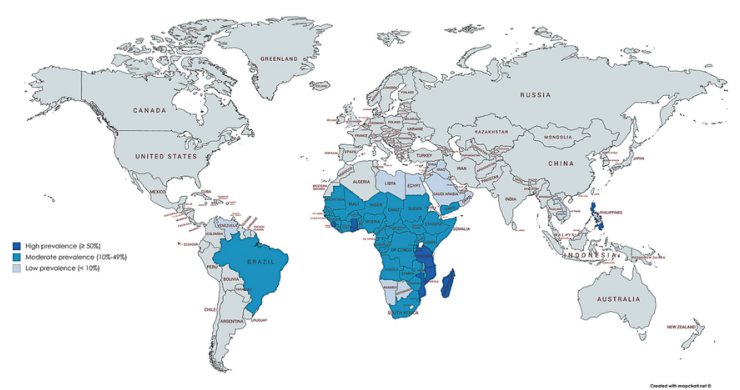

Panel A. Global distribution of schistomiasis [56]

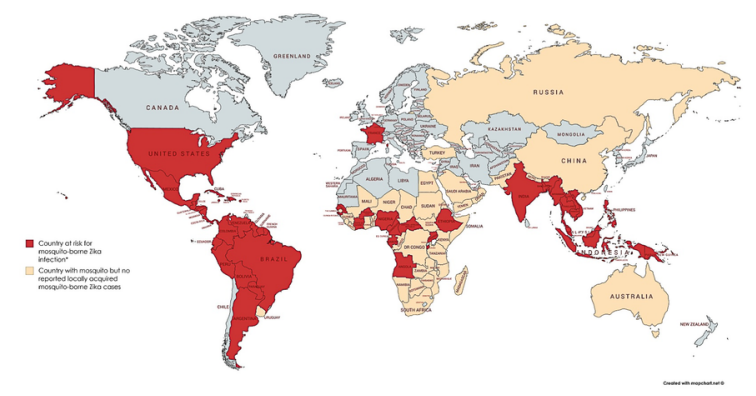

Panel B. Global distribution of Zika virus infection [72] 